\title{
Oil palm vegetation liquor: a new source of phenolic bioactives
}

Ravigadevi Sambanthamurthi ${ }^{1 *}$, YewAi $\operatorname{Tan}^{1}$, Kalyana Sundram ${ }^{2}$, Mahinda Abeywardena ${ }^{3}$, T. G. Sambandan ${ }^{4}$, ChoKyun Rha ${ }^{4}$, Anthony J. Sinskey ${ }^{4}$, Krishnan Subramaniam ${ }^{5}$, Soon-Sen Leow ${ }^{1}$, Kenneth C. Hayes ${ }^{6}$ and Mohd Basri Wahid ${ }^{1}$

${ }^{1}$ Malaysian Palm Oil Board, 6, Persiaran Institusi, Bandar Baru Bangi, 43000 Kajang Selangor, Malaysia

${ }^{2}$ Malaysian Palm Oil Council, 2nd Floor, Wisma Sawit, Lot 6, SS6, Jalan Perbandaran, 47301 Kelana Jaya,

Selangor, Malaysia

${ }^{3}$ Commonwealth Scientific and Industrial Research Organisation, Gate 13, Kintore Avenue, Adelaide, SA 5000, Australia

${ }^{4}$ Massachusetts Institute of Technology, 77 Massachusetts Avenue, Cambridge, MA 02139, USA

${ }^{5}$ MAHSA University College, Jalan University Campus, 59100 Kuala Lumpur, Malaysia

${ }^{6}$ Brandeis University, 415 South Street, Waltham, MA 02454, USA

(Received 14 October 2010 - Revised 31 January 2011 - Accepted 3 March 2011 - First published online 6 June 2011)

\section{Abstract}

Waste from agricultural products represents a disposal liability, which needs to be addressed. Palm oil is the most widely traded edible oil globally, and its production generates 85 million tons of aqueous by-products annually. This aqueous stream is rich in phenolic antioxidants, which were investigated for their composition and potential in vitro biological activity. We have identified three isomers of caffeoylshikimic acid as major components of oil palm phenolics (OPP). The 2,2-diphenyl-1-picrylhydrazyl assay confirmed potent free radical scavenging activity. To test for possible cardioprotective effects of OPP, we carried out in vitro LDL oxidation studies as well as ex vivo aortic ring and mesenteric vascular bed relaxation measurements. We found that OPP inhibited the Cu-mediated oxidation of human LDL. OPP also promoted vascular relaxation in both isolated aortic rings and perfused mesenteric vascular beds pre-contracted with noradrenaline. To rule out developmental toxicity, we performed teratological studies on rats up to the third generation and did not find any congenital anomalies. Thus, these initial studies suggest that OPP is safe and may have a protective role against free radical damage, LDL oxidation and its attendant negative effects, as well as vascular constriction in mitigating atherosclerosis. Oil palm vegetation liquor thus represents a new source of phenolic bioactives.

Key words: Oil palm phenolics: Caffeoylshikimic acid: Antioxidant activity: Teratology

Reactive oxygen species such as superoxide anions, $\mathrm{H}_{2} \mathrm{O}_{2}$ and hydroxyl radicals may contribute to the genesis of $\mathrm{CHD}$, diabetes, cancer and other degenerative diseases ${ }^{(1-5)}$. Many epidemiological studies have indicated that consumption of fruit and vegetables decreases the risk of degenerative diseases $^{(6,7)}$, and that the beneficial effects, in part, can be ascribed to the antioxidant activities of minor phytochemical components, including phenolic compounds ${ }^{(6-10)}$.

The oil palm (Elaeis guineensis) from the family Arecaceae is a high oil-producing tropical plant that appears to have an effective antioxidative component to counter the oxidative stress exerted by high temperature and intense sunlight. Indeed, the oil palm is a rich source of phytochemicals ${ }^{(11-13)}$. While the technology for recovery of fat-soluble antioxidants such as tocopherols, tocotrienols and carotenoids from palm oil is well established ${ }^{(11)}$, it is only recently that the technology for harvesting water-soluble antioxidants from oil palm has become available ${ }^{(12,14-17)}$.

During the palm oil milling process, water-soluble phenolics are discarded in the waste stream, amounting to 85 million tons per year globally. A recovery procedure for oil palm phenolics (OPP) has been developed to isolate concentrations ${ }^{(14)}$ suitable for biological applications, providing an opportunity to transform a bioburden into a range of potential applications for health and wellness.

Based on growing evidence that plant phenolics are beneficial to health, OPP was assessed for positive bioactivities. In the present study, the chemical constituents and composition of specific OPP are described. In addition, in vitro antioxidant and LDL oxidation experiments, as well as ex vivo aortic ring and mesenteric vascular bed experiments, were designed to identify the potential bioactivities of OPP.

Abbreviations: DPPH, 2,2-diphenyl-1-picrylhydrazyl; OPP, oil palm phenolics.

*Corresponding author: R. Sambanthamurthi, fax +60 38926 1995, email raviga@mpob.gov.my 
We also carried out teratological studies to assess whether OPP is safe for consumption.

\section{Materials and methods}

\section{HPLC, MS and NMR analyses of oil palm phenolics}

OPP obtained according to the methods described by Sambanthamurthi et al. ${ }^{(14)}$ was subjected to separation by reversed-phase HPLC, and the individual peaks were characterised by MS and NMR spectroscopy. A freeze-dried OPP sample $(10 \mathrm{mg})$ was dissolved in $1 \mathrm{ml}$ of internal standard citric acid solution ( $\alpha$-cyano-hydroxycinnamic acid $(1 \mathrm{mg} / \mathrm{ml})$ in $0.2 \%(\mathrm{v} / \mathrm{v})$ citric acid). The OPP sample was then extracted by adding $1 \mathrm{ml}$ of ethyl acetate, shaking the solution well and then allowing it to settle. The supernatant $(200 \mu \mathrm{l})$ was evaporated and reconstituted with $200 \mu \mathrm{l}$ of $0 \cdot 2 \%$ (v/v) citric acid. This reconstituted solution was then injected into an analytical HPLC system. Each compound in the sample was determined using the peak ratio of the compound $v$. the internal standard. The calibration curve was used to obtain the concentration of each compound based on their peak ratios.

Samples were analysed on a Hitachi system comprising a low-pressure mixing pump (model L7100; Hitachi, Richmond, CA, USA), an autosampler (model L7200; Hitachi), a photodiode detector (L7450; Hitachi) and D-7000 HPLC system software for integration (Hitachi). Chromatographic separation was achieved using a $250 \times 4.0 \mathrm{~mm}$ reversed-phase column (GL Exsil ODS $5 \mu \mathrm{m}$ inner diameter) (SGE Inc., Austin, TX, USA). The mobile phase used was a binary gradient system, with phase A comprising $10 \mathrm{~mm}$-sodium sulphate containing $0.02 \%(\mathrm{v} / \mathrm{v})$ phosphoric acid ( $\mathrm{pH} 2.75)$ and phase B comprising methanol-acetonitrile (70:30, v/v). Sample injection volume was $10 \mu \mathrm{l}$ and a flow rate of $0.8 \mathrm{ml} / \mathrm{min}$ was used. The gradient elution with a total run time of $60 \mathrm{~min}$ was as follows: started from $95 \%(\mathrm{v} / \mathrm{v})$ solvent A and 5\%(v/v) solvent $\mathrm{B}$, increased to $35 \%(\mathrm{v} / \mathrm{v})$ solvent $\mathrm{B}$ over $45 \mathrm{~min}$, then increased to $100 \%(\mathrm{v} / \mathrm{v})$ solvent $\mathrm{B}$ over $3 \mathrm{~min}$, then maintained at $100 \%(\mathrm{v} / \mathrm{v})$ solvent $\mathrm{B}$ for $2 \mathrm{~min}$ and finally decreased to $5 \%(\mathrm{v} / \mathrm{v})$ solvent B over $10 \mathrm{~min}$. A MALDI Voyager (Applied Biosystems, Foster City, CA, USA) was used to determine the molecular weights of these compounds. ${ }^{1} \mathrm{H}$ NMR and ${ }^{13} \mathrm{C}$ NMR were carried out with a Varian Inova600 (600 MHz) equipped with a $5 \mathrm{~mm}$ inner diameter probe (Varian, Inc., Walnut Creek, CA, USA).

\section{Analysis of oil palm phenolics antioxidant activity}

The phenolic content of OPP used in animal studies was determined using the Folin-Ciocalteu reagent ${ }^{(18)}$. The free radical scavenging activity was assessed using the 2,2-diphenyl-1-picrylhydrazyl (DPPH) reagent ${ }^{(9)}$.

\section{Copper-mediated LDL oxidation}

To evaluate the ability of OPP to inhibit Cu-mediated LDL oxidation, conjugated dienes were continually monitored at 5 min intervals at $37^{\circ} \mathrm{C}$ by UV absorption at $234 \mathrm{~nm}$. LDL was prepared as described by Sundram et al. ${ }^{(19)}$. LDL oxidation was initiated by the addition of copper sulphate at a final concentration of $6 \mu \mathrm{mol}-90 \mu \mathrm{g}$ of LDL-cholesterol in a final volume of $1 \mathrm{ml}$. Purified catechin was used as a control phenolic compound. The purified test compounds (catechin obtained from Sigma Chemical, St Louis, MO, USA) and OPP extracts were added immediately before the addition of the oxidant. All LDL oxidations were performed in triplicates. The lag time in the presence or absence of the test compounds was determined as the intercept of the slopes for the lag and propagation phases. This was compared with the control oxidised LDL to determine the percentage LDL oxidation inhibition.

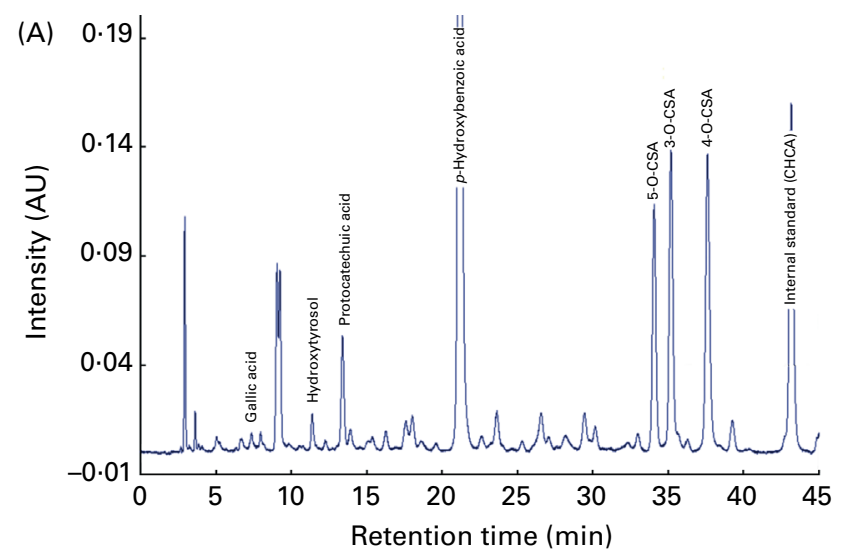

(B)
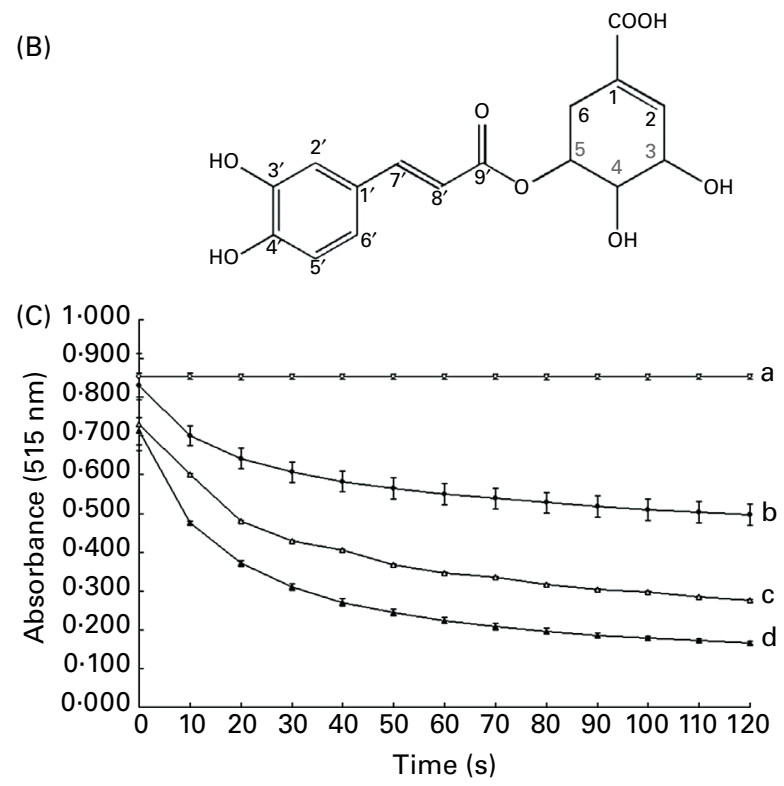

Fig. 1. Components and antioxidant activity of oil palm phenolics (OPP). (A) HPLC profile of OPP indicating the presence of compounds such as hydroxytyrosol, $p$-hydroxybenzoic acid, protocatechuic acid and three isomers of caffeoylshikimic acid (CSA). $\alpha$-Cyano-hydroxycinnamic acid (CHCA), an internal standard used in the HPLC analysis for quantification of the OPP components. (B) Structure of 5-O-CSA. (C) Antioxidant activity expressed as free radical scavenging activity (inhibition of 2,2-diphenyl-1-picrylhydrazyl). Lines with unlike letters were significantly different from one another (two-tailed unpaired Student's $t$ test, $P<0.01$, compared with a). $-\bigcirc-$, Blank; -๑-, $100 \mathrm{mg} / \mathrm{l}$ gallic acid equivalents (GAE); $-\triangle, 200 \mathrm{mg} / \mathrm{l} \mathrm{GAE} ;-\mathbf{\Lambda}-$, $300 \mathrm{mg} / \mathrm{l} \mathrm{GAE} . \mathrm{AU}$, arbitrary units. 
Table 1. Concentrations of major phenolic components in oil palm phenolics (OPP)*

(Mean values, standard deviations and ranges)

\begin{tabular}{|c|c|c|c|}
\hline \multirow[b]{2}{*}{ Phenolic compounds } & \multicolumn{3}{|c|}{ Concentration (mg/kg) } \\
\hline & Mean & SD & Range \\
\hline Protocatechuic acid & 600 & 100 & $400-800$ \\
\hline$p$-Hydroxybenzoic acid & 7000 & 1000 & $5300-8600$ \\
\hline $\begin{array}{l}\text { Caffeoylshikimic acid (total } \\
\text { of three isomers) }\end{array}$ & 10800 & 2400 & $7700-15100$ \\
\hline Total major phenolics & 18400 & 2900 & $13800-24300$ \\
\hline Gallic acid equivalents & 18200 & 1700 & $15700-21300$ \\
\hline
\end{tabular}

\section{Aortic ring and mesenteric vascular bed preparation for} vascular studies

The use of animals in the present study was approved by the Commonwealth Scientific and Industrial Research Organisation-Health Sciences and Nutrition Animal Experimentation Ethics Committee. All experimental procedures including the care, handling and maintenance of the experimental animals were performed according to the National Health and Medical Research Council guidelines for the use and care of animals for experimental purposes.

Isolated segments $(3 \mathrm{~mm})$ of the thoracic aorta from male normotensive Wistar Kyoto and spontaneously hypertensive rats (12-14 weeks old) supplied by the Animal Resources Centre (Canning Vale, WA, Australia) were mounted under isometric conditions in $15 \mathrm{ml}$ organ bath chambers containing physiological Krebs-Henseleit solution (113 mm-NaCl, $4.8 \mathrm{~mm}$ potassium chloride, $1.2 \mathrm{~mm}_{-} \mathrm{KH}_{2} \mathrm{PO}_{4}, 1.2 \mathrm{~mm}_{-} \mathrm{MgSO}_{4}, 25 \mathrm{~mm}$ $\mathrm{NaHCO}_{3}, 2.5 \mathrm{~mm}-\mathrm{CaCl}_{2}, 11.2 \mathrm{~mm}$-glucose and $0.57 \mathrm{~mm}$-ascorbic acid in Milli Q-treated water), bubbled with carbogen and maintained at $37^{\circ} \mathrm{C}$ as described in detail previously ${ }^{(20,21)}$. In some rings, the endothelium was removed by careful rubbing of the intima with a moistened cotton swab. The tissues were equilibrated for at least $60 \mathrm{~min}$ before contracting with potassium chloride $(20 \mathrm{mmol} / \mathrm{l})$ to test tissue viability. The rings were pre-contracted with half maximal dose of noradrenaline. Concentrated OPP preparation was dissolved and diluted serially with buffer and added in cumulatively, directly to the bath. The change in tension was monitored using a computerised data acquisition system, and the extent of relaxation was calculated (BIOPAC Systems, Inc., Goleta, CA, USA).

The mesenteric arterial bed was prepared as described earlier ${ }^{(20,22)}$. The superior mesentery artery was cannulated and flushed with heparin saline, and the entire mesenteric bed including the intestinal tract was removed and the gut content was flushed out with saline. The preparation was mounted in a $50 \mathrm{ml}$ organ bath chamber and continuously perfused with oxygenated Krebs-Henseleit medium. After 30 min of equilibration, tissue viability was assessed by cumulative intraluminal injection of various agonists (potassium chloride, noradrenaline). The pressure was raised by the addition of noradrenaline (half maximal dose) in the bath perfusate.
Vasorelaxation response to the pharmacological agent acetylcholine (positive control) and OPP was determined by measuring the pressure reduction following intraluminal administration. Pressure changes were monitored using the MLT844 Physiological Pressure Transducer connected to a pressure amplifier (DA100C; BIOPAC Systems, Inc.) and a computer-based data acquisition system (MP100WSW Highperformance data acquisition unit; BIOPAC Systems, Inc.).

\section{Teratological studies}

The present study was designed to conform as closely as possible and, where applicable, to the United States Food and Drug Administration (US FDA) Department of Health and Human Services' Guidelines. The present study was also guided by a document of the FDA's Office of Food Additive Safety's Redbook 2000 (Toxicological Principles for the Safety Assessment of Food Additives). In conforming to the General Guidelines for Toxicology Studies' Good Laboratory Practice, the laboratory studies were conducted according to the US FDA Good Laboratory Practice regulations, issued under Part 58, Title 21 (Code of Federal Regulations). Female Albino Sprague-Dawley rats were obtained from the animal house facility at the Medical Faculty of University of Malaya (Kuala Lumpur, Malaysia). Ethical clearance was given by the Animal Care and Use Committee of the University of Malaya.

Female Albino Sprague-Dawley rats weighing about $200 \mathrm{~g}$ were mated, and the presence of the vaginal plug was taken to confirm pregnancy. Pregnant females were isolated in individual stainless-steel cages under the controlled conditions of the animal experimental unit. All rats were given standard rat chow. The controls were given water, while test rats were ad libitum given 1500 or $2400 \mathrm{mg} / \mathrm{l}$ gallic acid equivalent OPP as the sole drinking fluid from the day the vaginal plug was seen until the exact day of delivery (21-22d).

The pregnant mothers were carefully monitored at least once daily. No abnormal behaviour was observed. The rats were weighed daily. The number of surviving pups at birth was noted, and any subsequent deaths or pups missing due to cannibalisation by the mother were also noted. After delivery, the rat pups and their mothers were kept in their

Table 2. Effect of oil palm phenolics (OPP) on copper-mediated oxidation of human $\mathrm{LDL}^{*}$

(Mean values and standard deviations, $n 6$ (LDL preparations))

\begin{tabular}{lcr}
\hline & \multicolumn{2}{c}{ Lag time (min) } \\
\cline { 2 - 3 } Test compounds & Mean & SD \\
\hline LDL (control) & 67 & 12 \\
OPP $(0.25 \mathrm{mg} / \mathrm{kg})$ & 74 & 9 \\
OPP $(0.50 \mathrm{mg} / \mathrm{kg})$ & $103 \dagger$ & 14 \\
OPP $(1.00 \mathrm{mg} / \mathrm{kg})$ & $121 \dagger$ & 7 \\
Catechin $(0.25 \mathrm{mg} / \mathrm{kg})$ & 87 & 13 \\
Catechin $(0.50 \mathrm{mg} / \mathrm{kg})$ & $104 \dagger$ & 10 \\
\hline
\end{tabular}

* All oxidations were conducted in triplicate and averaged for each LDL preparation.

$\dagger$ Mean values were significantly different from LDL (control; $P<0.05$ ) 
stainless-steel cages. Standard rat chow and water were given to both the control and test mothers. The pups were kept with their mothers at all times except when observations and measurements were made. Except for those killed (by an overdose of chloral hydrate) for histological studies, the remaining pups were allowed to grow into adults, and the mating, feeding and other procedures were repeated twice (second and third generation).

Before necropsy and microscopic studies, the rat pups were observed from birth until $21 \mathrm{~d}$ after birth. Measurements or observations were recorded at birth, as well as 7, 14 and $21 \mathrm{~d}$ after birth.

The external parameters that were measured were body weight $(\mathrm{g})$, nose-rump length $(\mathrm{mm})$, tail length $(\mathrm{mm})$ and tibial length (right and left sides) (mm). The physical examinations were carried out to assess exencephaly, eye defects (external), cleft palate, cleft lip, maxillofacial development, hydrocephalus, integument, locomotion, equilibrium and muscular tremors or abnormal movements.

The standard protocol for inspection of internal organs was carried out, and no obvious abnormalities or defects were observed, so it was concluded that no gross anomalies had developed. The organs were then harvested and processed for histopathology. Wax sections cut at $5 \mu \mathrm{m}$ in thickness

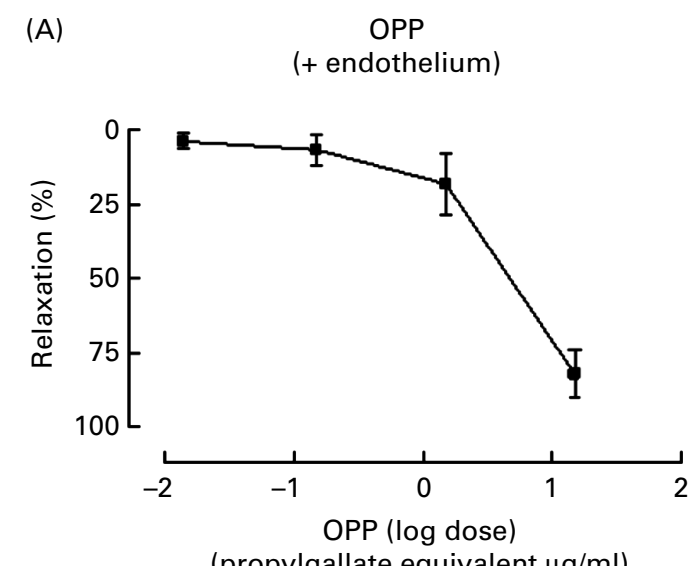

(B)

(propylgallate equivalent $\mu \mathrm{g} / \mathrm{ml}$ )

OPP

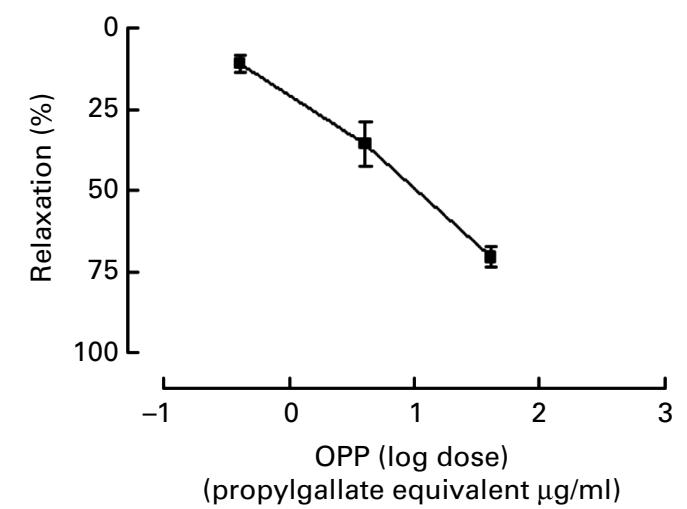

were mounted onto glass slides and stained with haematoxylin and eosin for light microscopy.

\section{Statistical analysis}

Data were analysed using the Statistical Analysis System program (SAS Institute Inc., Cary, NC, USA). The experimental results are expressed as means and standard deviations, unless otherwise stated. For comparison of two groups, two-tailed unpaired Student's $t$ test was performed, and significant differences between means were determined. For all outcomes, $P<0.05$ was considered statistically significant.

\section{Results and discussion}

\section{Oil palm phenolic components}

Characterisation of the composition of OPP has been achieved using HPLC separation followed by MS and NMR. OPP contains numerous phenolic acids including caffeic acid, protocatechuic acid and $p$-hydroxybenzoic acid. We found that OPP also contains three isomers of caffeoylshikimic acid, a group of unique signature phenolics (Fig. 1(A) and (B)), as major components. The NMR data are given in the recently filed

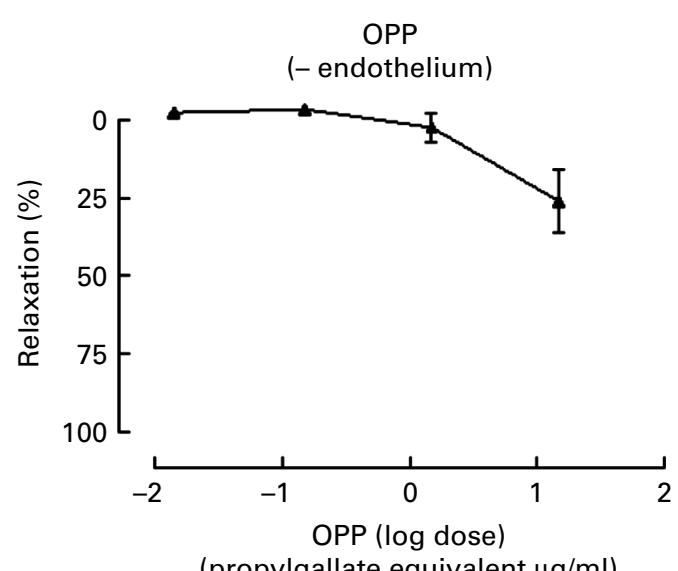

(propylgallate equivalent $\mu \mathrm{g} / \mathrm{ml}$ )

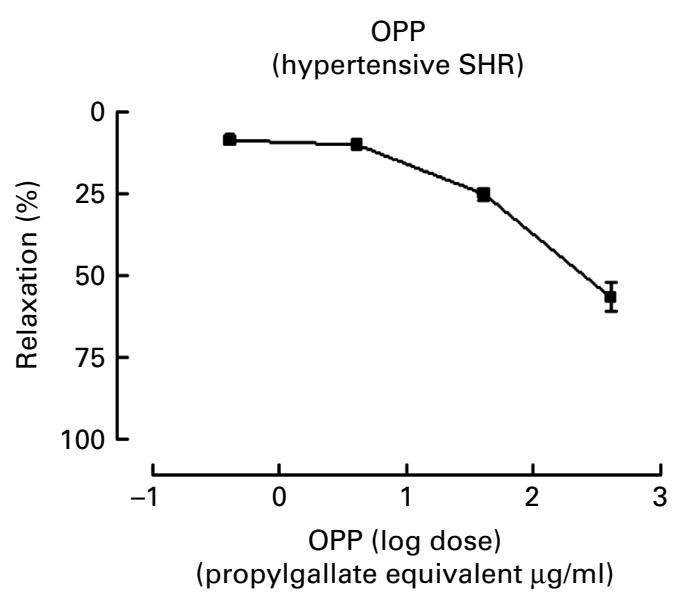

Fig. 2. Vascular relaxation actions of oil palm phenolics (OPP). (A) Responses following cumulative addition of OPP to endothelium intact and denuded aortic rings from normotensive rats. (B) Responses following intraluminal administration of OPP to a perfused mesenteric vascular bed from normotensive and spontaneously hypertensive rats. Values are means, with their standard errors represented by vertical bars ( $n$ 6). WKY, Wistar Kyoto; SHR, spontaneously hypertensive rat. 
international patent ${ }^{(23)}$. The major contributors to the total phenolics are caffeoylshikimic acid at 10800 (SD $2400) \mathrm{mg} / \mathrm{kg}$, followed by $p$-hydroxybenzoic acid at 7000 (SD 1000) $\mathrm{mg} / \mathrm{kg}$ (Table 1).

The only other plant where caffeoylshikimic acid has been reported to be a major phenolic constituent is the date palm, Phoenix dactylifera ${ }^{(24)}$. In this fruit, 3-O-caffeoylshikimic acid, also known as dactylifric acid, has been identified as one of the main enzymic browning substrates. The two isomers 4-O-caffeoylshikimic acid and 5-O-caffeoylshikimic acid are also known as isodactylifric and neodactylifric acid, respectively. Caffeoylshikimic acids represent one of the resistance factors of date palm roots towards Fusarium oxysporum ${ }^{(25,26)}$. In addition, caffeoylshikimic acid has been identified as a minor constituent of yerba mate (Ilex paraguariensis L.) ${ }^{\text {(27) }}$ and vaccinium plants, lingonberry (Vaccinium vitis-idaea L.), bilberry (Vaccinium myrtillus L.) and hybrid bilberry $\left(\right.$ Vaccinium $\times$ intermedium Ruthe L.) ${ }^{(28)}$.

Shikimic acid and its esters are not commonly found in nature. It is likely that these compounds do not accumulate to an appreciable extent in most plants owing to their high metabolic turnover. For example, shikimic acid is central to the biosynthetic pathway for aromatic compounds such as tyrosine, tryptophan, phenylalanine and lignins, resulting in the rapid utilisation of this metabolite in plants. Caffeoylshikimic acid accounts for more than half of the total phenolic content of OPP, making it the largest known source of this compound.

\section{Antioxidant potential of oil palm phenolics}

When the free radical scavenging activity of OPP was measured by DPPH in a standard assay ${ }^{(9)}$, OPP showed significant scavenging activity with a $t_{1 / 2}$ (time to scavenge $50 \%$ of the initial DPPH radicals) of less than $30 \mathrm{~s}$ at all concentrations tested (Fig. 1(C)). More than $75 \%$ of the DPPH were scavenged by OPP at $100 \mathrm{mg} / \mathrm{l}$ gallic acid equivalent. The high efficacy and rate of free radical scavenging of OPP are generally indicative of protective antioxidant applications in vivo. Antioxidant activity of OPP is attributed to the ability to scavenge free radicals and donate hydrogen atoms. The antioxidant and radical scavenging activities increase with the degree of hydroxylation of the phenolic compound ${ }^{(29)}$. Caffeoylshikimic acid has four hydroxyl groups, and this would account for the potent antioxidant activity of OPP. Bearing in mind that OPP also has other phenolic acids present such as protocatechuic acid and $p$-hydroxybenzoic acid, these would also be expected to contribute to the antioxidant activity observed. Working together, these phenolic acids may also have a synergistic effect.

Pomace and other milling wastes have been reported to be rich in phenolics. However, these usually exist in the conjugated form with sugars and other moieties ${ }^{(30,31)}$. These conjugation reactions occur via the hydroxyl groups of phenolics, thus reducing the degree of hydroxylation and hence the antioxidant potential. Enzymatic hydrolysis of these glycosylated phenolics has been suggested as an attractive means of releasing free phenolics and hence, increasing their antioxidant potential ${ }^{(30,31)}$. Fortuitously, in the case of OPP, the sterilisation process during oil palm milling would hydrolyse glycosylated phenolics, releasing unconjugated phenolic acids such as caffeoylshikimic acids. OPP thus resembles coffee in that it consists mainly of phenolic acids and not flavonoids. Coffee consists of chlorogenic acids, which are a group of compounds comprising hydroxycinnamic acids, such as caffeic acid, ferulic acid and $p$-coumaric acid, linked to quinic acid to form a range of conjugated structures known as caffeoylquinic acids, feruloylquinic acids and $p$-coumaroylquinic acids ${ }^{(32)}$. Coffee has been reported to have higher antioxidant activities when compared with tea and cocoa on a cup-serving basis ${ }^{(33)}$.

\section{Protection against $L D L$ oxidation}

Oxidation of LDL has a pathogenic role in the development of atherosclerosis $^{(34)}$. Uptake of oxidised LDL by macrophages and smooth muscle cells leads to the development of fatty streaks, a key event in early atherosclerosis. There is a positive correlation between the resistance of LDL to oxidation and the severity of coronary atherosclerosis in human subjects ${ }^{(35)}$. In the present study, OPP dose-dependently inhibited the Cu-mediated oxidation of human LDL in vitro. It increased the lag time of conjugated diene formation from 67 (control) to 74,103 and $121 \mathrm{~min}$ at concentrations of $0.25,0.50$ and $1.00 \mathrm{mg} / \mathrm{kg}$ gallic acid equivalent, respectively, implying potential efficacy against atherogenesis. A commercial preparation of pure catechin showed a similar effect (Table 2). The results are consistent with other investigations carried out using wine, cocoa and green tea, showing positive correlations between inhibition of LDL oxidation and the amount of total phenolic compounds ${ }^{(36-38)}$. Phenolics prevent LDL oxidation in vitro by scavenging radical species or sequestering metal ions ${ }^{(39,40)}$. This protection by phenolics indicates a decreased risk of CVD when changes in the susceptibility and extent of LDL oxidation are implicated as important causative factors.

\section{Aortic ring and mesenteric vascular bed vascular relaxation}

Isolated vascular preparations such as the aortic ring and perfused mesenteric vascular bed have routinely been used as reliable in vitro methods to investigate the vascular actions of therapeutic agents as well as potential bioactives. This model allows the investigation of potential vasodilatory effects including an assessment of the role of vascular endothelium in mediating potential benefits. Endothelial-derived NO induces vasodilation by diffusing across the endothelium into the adjacent smooth muscle, causing the smooth muscle to relax and dilate. $\mathrm{NO}$ is produced from L-arginine in a reaction catalysed by endothelial NO synthase.

To assess for possible vascular protection effects, we used aortic ring and mesenteric vascular bed preparations in the present study. OPP dose-dependently promoted vascular relaxation in endothelium-intact isolated aortic rings (conductance vessels) and in a perfused mesenteric vascular bed (resistance vessels) (Fig. 2). These results indicate that the 

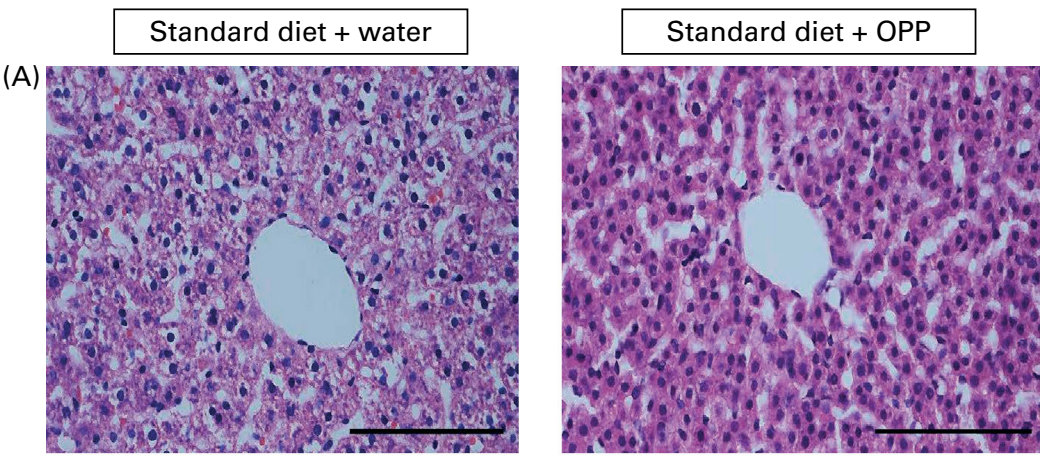

(B)
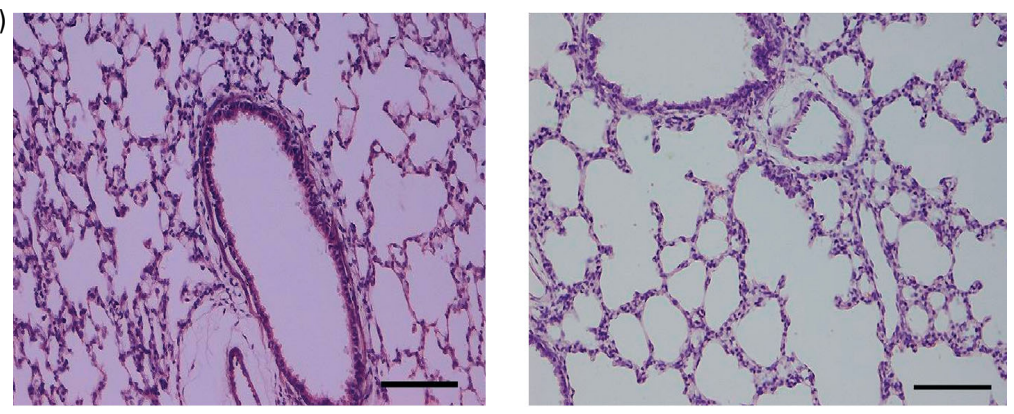

(C)
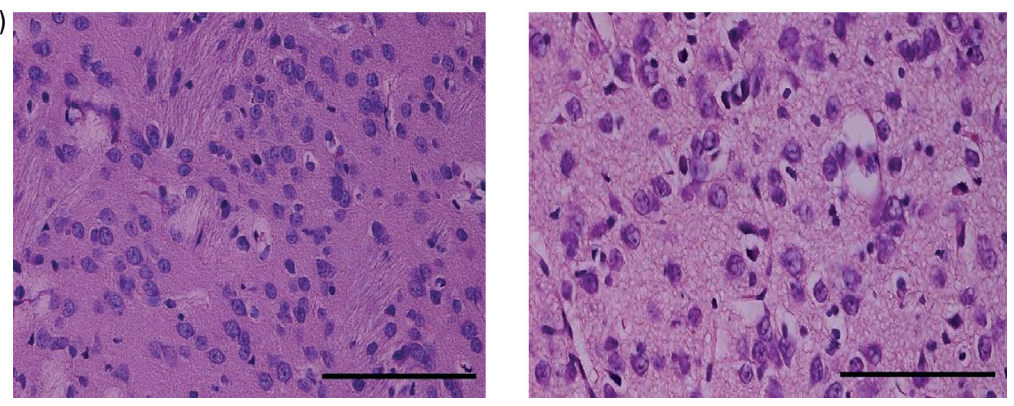

(D)
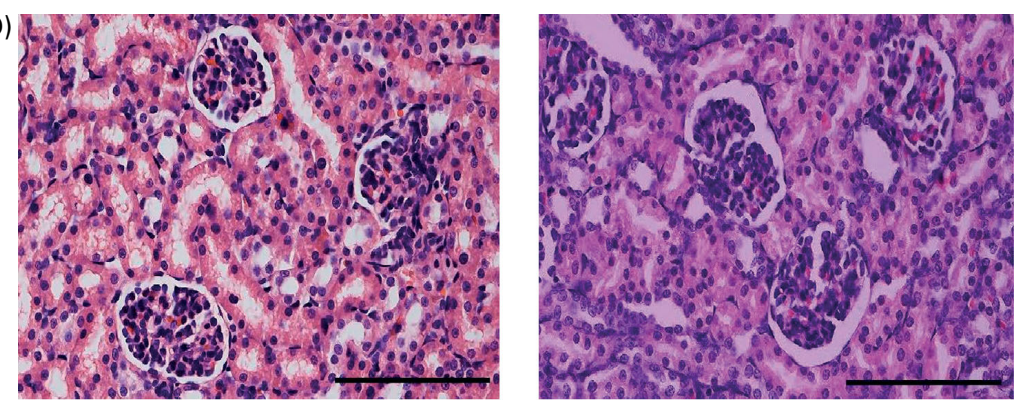

(E)
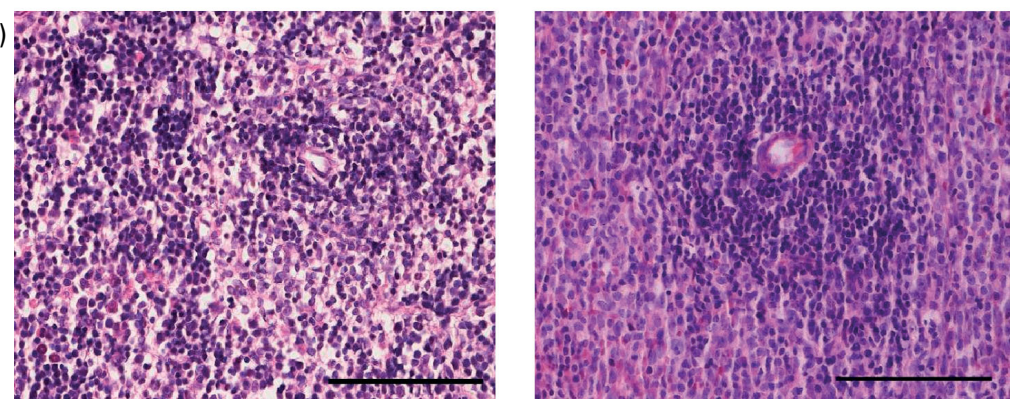

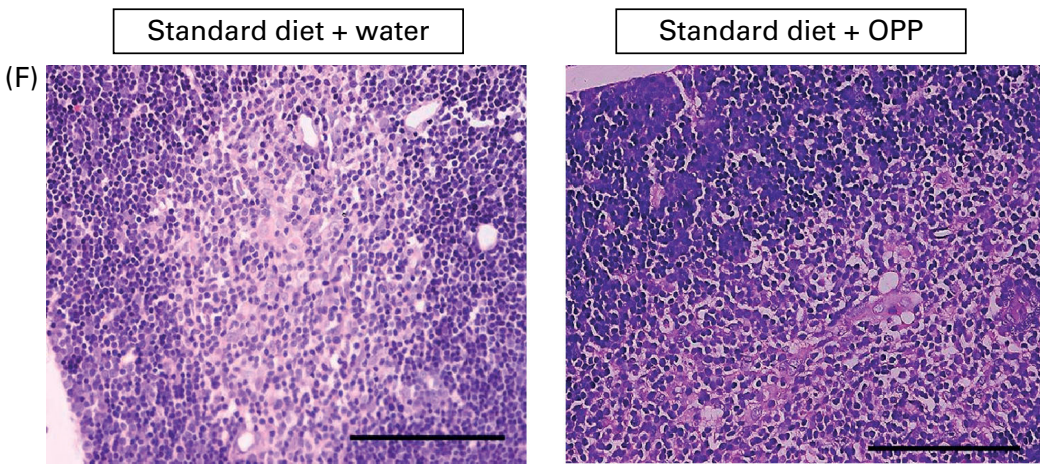

(G)
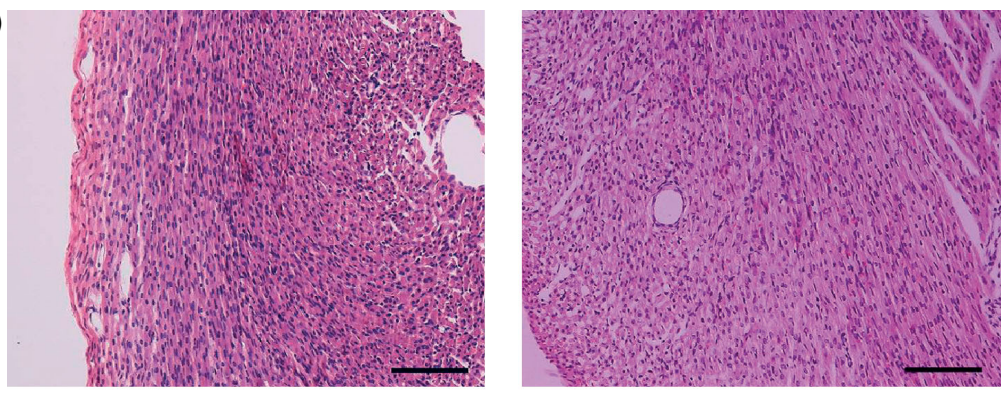

(H)
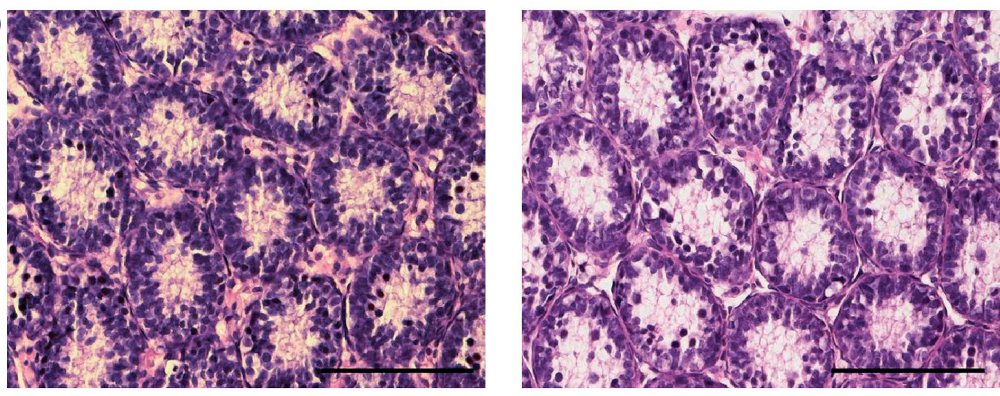

(I)
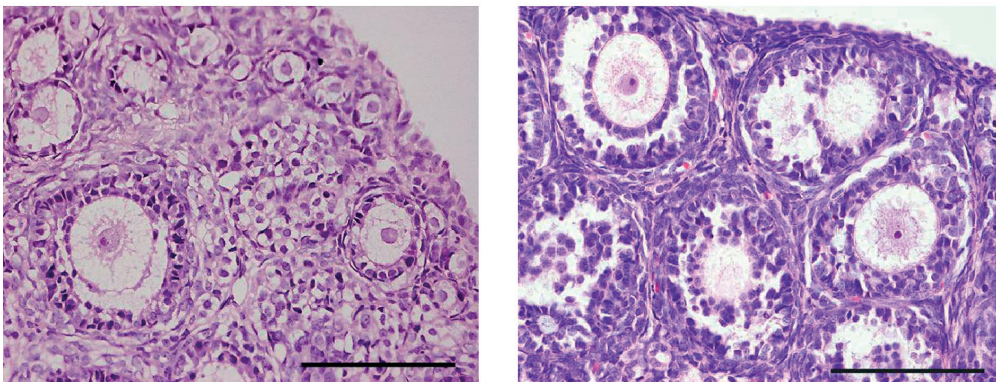

Fig. 3. Representative haematoxylin and eosin-stained tissue slices from major organs of third-generation rats viewed under a light microscope. (A) Liver (B) lung, (C) brain, (D) kidney, (E) spleen, $(\mathrm{F})$ thymus, $(\mathrm{G})$ heart, $(\mathrm{H})$ testis and (I) ovary. Oil palm phenolics (OPP) did not show teratogenic effects. Scale bars represent $100 \mu \mathrm{m}$.

vascular relaxation induced by OPP was mediated via endothelial NO, a major endogenous vasodilator involved in maintaining cardiovascular homeostasis.

In physiological terms, the aorta does not contribute to peripheral vascular resistance. However, changes in vascular reactivity and compliance in larger vessels (stiffness-elasticity) may influence vascular flow characteristics. Indeed, a large body of evidence indicates that different plant-based compounds, which showed positive results in the aortic ring preparation (e.g. grape and wine polyphenols, cocoa and coffee phenolics, soya isoflavones), have also been found to produce vasodilation and improve vascular function in whole animals and in human subjects ${ }^{(41-47)}$.

The mesenteric vascular bed is an important contributor to systemic vascular resistance, and compared with the larger vessels such as the aorta, contractions of smaller arteries are more relevant to blood pressure regulation. It is known that both an increased cardiac output and an increased vascular resistance in the peripheral circulation can lead to hypertension. Therefore, tissue preparations, which measure vascular function in resistance vessels, can be regarded as more relevant for studies on blood pressure regulation and 
hypertension. In the perfused mesenteric preparation, the changes in intraluminal pressure development due to the constriction of resistance arteries (peripheral circulation) are measured. The present findings that OPP dose-dependently promoted relaxation in both larger vessels (aorta) and resistance vessels suggest that this mix of phenolics may be effective in lowering blood pressure in the whole animal.

\section{Teratological studies}

Administration of OPP to rats did not affect the well-being of the animals, and no signs of OPP-induced toxicity were observed, as determined by gross morphological examination of major organs. We also ruled out teratogenic effects by monitoring Sprague-Dawley rats for three generations. There were no observable developmental birth defects or congenital anomalies in the offspring of rats supplemented with OPP at both 1500 and $2400 \mathrm{mg} / \mathrm{l}$ gallic acid equivalents in their water supply for all three generations tested. There was no significant difference in the number of surviving offspring. Physical examinations including macroscopic observations for exencephaly, external eye defects, cleft palate/lip, maxillofacial development, hydrocephalus, integument, locomotion, equilibrium and muscular tremors did not reveal any abnormalities caused by OPP. The growth milestones of the offspring were also not significantly different from the controls for the three generations studied. The histology of all organs tested, including liver, lungs, brain, kidneys, spleen, thymus, heart, testes and ovaries, was normal (Fig. 3). The weights of the organs tested were also not significantly different.

\section{Conclusions}

The burden of chronic diseases is rapidly increasing worldwide. Oxidative stress is a unifying mechanism in the aetiology of chronic diseases. As such, dietary antioxidants such as widespread plant phenolics may be important for the prevention and treatment of chronic diseases. The discovery that the aqueous stream of the oil palm milling process contains potent phenolics raises the possibility that a major disposal liability can be turned into beneficial use against chronic disease processes. It has been established that phenolic compounds in wastewaters from oil milling industries are toxic to plants and micro-organisms. Removal of phenolic compounds from these wastewaters has been shown to attenuate toxicity ${ }^{(48)}$. Thus, the palm oil mill effluent discharged following removal of phenolics is expected to be less toxic. The present data indicate that caffeoylshikimic acids, which are rare in nature, are the major components of OPP. The present study also confirmed that OPP displays antioxidant properties with potentially far-reaching physiological effects without evidence of toxicity. In conclusion, OPP from the aqueous stream of the palm oil milling process has significant protective bioactivities against CVD, without causing toxicities and teratological effects in pre-clinical models. This discovery makes it possible to turn a major disposal liability into a unique, potentially valuable resource for pharmaceutical and healthcare functions.

\section{Acknowledgements}

The present study was fully supported by the Malaysian Palm Oil Board. There are no conflicts of interest. R. S. conceived the study, participated in its design and coordination, and drafted and edited the manuscript. R. S. also prepared the OPP extract and carried out the in vitro antioxidant assays. Y. A. T. participated in the conception and design of the study, preparation of OPP and drafting of the manuscript. $\mathrm{K}$. Sun was involved in the conception and design of the study. M. A. performed the vascular relaxation studies. T. G. S., C. K. R. and A. J. S. carried out the OPP characterisation and fingerprinting studies. K. Sub. carried out the teratological and histological studies. S.-S. L. was involved in the in vitro antioxidant study and editing of the manuscript. K. C. H. was involved in the initial stages of setting up the study and preliminary drafting of the manuscript. M. B. W. participated in the design of the study. All authors participated in helpful discussions and read as well as approved the final manuscript. The authors also gratefully acknowledge the technical assistance of the staff of Metabolics and Analytical Research Laboratories of the Malaysian Palm Oil Board.

\section{References}

1. Nakazono K, Watanabe N, Matsuno K, et al. (1991) Does superoxide underlie the pathogenesis of hypertension? Proc Natl Acad Sci U S A 88, 10045-10048.

2. Griendling KK \& Alexander RW (1997) Oxidative stress and cardiovascular disease. Circulation 96, 3264-3265.

3. Givertz MM \& Colucci WS (1998) New targets for heartfailure therapy: endothelin, inflammatory cytokines, and oxidative stress. Lancet 352, Suppl. 1, SI34-SI38.

4. Yokoyama H, Kuroiwa H, Yano R, et al. (2008) Targeting reactive oxygen species, reactive nitrogen species and inflammation in MPTP neurotoxicity and Parkinson's disease. Neurol Sci 29, 293-301.

5. Ha H, Hwang IA, Park JH, et al. (2008) Role of reactive oxygen species in the pathogenesis of diabetic nephropathy. Diabetes Res Clin Pract 82, Suppl. 1, S42-S45.

6. Vieira de Almeida LM, Pineiro CC, Leite MC, et al. (2008) Protective effects of resveratrol on hydrogen peroxide induced toxicity in primary cortical astrocyte cultures. Neurochem Res 33, 8-15.

7. Lu KT, Ko MC, Chen BY, et al. (2008) Neuroprotective effects of resveratrol on MPTP-induced neuron loss mediated by free radical scavenging. J Agric Food Chem 56, 6910-6913.

8. Hwang JT, Kwon DY, Park OJ, et al. (2008) Resveratrol protects ROS-induced cell death by activating AMPK in H9c2 cardiac muscle cells. Genes Nutr 2, 323-326.

9. Yu L, Perret J, Harris M, et al. (2003) Antioxidant properties of bran extracts from "Akron" wheat grown at different locations. J Agric Food Chem 51, 1566-1570.

10. Balasundram N, Tan YA, Sambanthamurthi R, et al. (2005) Antioxidant properties of palm fruit extracts. Asia Pac J Clin Nutr 14, 319-324.

11. Sambanthamurthi R, Sundram K \& Tan Y (2000) Chemistry and biochemistry of palm oil. Prog Lipid Res 39, 507-558.

12. Sundram K, Sambanthamurthi R \& Tan YA (2003) Palm fruit chemistry and nutrition. Asia Pac J Clin Nutr 12, 355-362.

13. Tan YA, Sambanthamurthi R, Sundram K, et al. (2007) Valorisation of palm by-products as functional components. Eur J Lipid Sci Technol 109, 380-393. 
14. Sambanthamurthi R, Tan YA \& Sundram K (2008) Treatment of vegetation liquors derived from oil-bearing fruit. United States Patent US 7,387,802 B2: Malaysian Palm Oil Board.

15. Neo YP, Ariffin A, Tan CP, et al. (2008) Determination of oil palm fruit phenolic compounds and their antioxidant activities using spectrophotometric methods. Int J Food Sci Technol 43, 1832-1837.

16. Chakraborty M, Das K, Dey G, et al. (2006) Unusual high quantity of 4-hydroxybenzoic acid accumulation in cell wall of palm mesocarp. Biochem Sys Ecol 34, 509-513.

17. Holland L (2001) Does oil palm hold a cancer cure? Far Eastern Economic Review 164, 56.

18. Gao X, Ohlander M, Jeppsson N, et al. (2000) Changes in antioxidant effects and their relationship to phytonutrients in fruits of sea buckthorn (Hippophae rhamnoides L.) during maturation. J Agric Food Chem 48, 1485-1490.

19. Sundram K, Hornstra G, von Houwelingen AC, et al. (1992) Replacement of dietary fat with palm oil: effect on human serum lipids, lipoproteins and apolipoproteins. Br J Nutr 68, 677-692.

20. Runnie I, Salleh MN, Mohamed S, et al. (2004) Vasorelaxation induced by common edible tropical plant extracts in isolated rat aorta and mesenteric vascular bed. J Ethnopharmacol 92, 311-316.

21. Abeywardena MY, Jablonskis LT \& Head RJ (2002) Age- and hypertension-induced changes in abnormal contractions in rat aorta. J Cardiovasc Pharmacol 40, 930-937.

22. Longhurst PA, Stitzel RE \& Head RJ (1986) Perfusion of the intact and partially isolated rat mesenteric vascular bed: application to vessels from hypertensive and normotensive rats. Blood Vessels 23, 288-296.

23. Sambandan TG, Rha CK \& Sinskey AJ, et al. (2010) Composition comprising caffeoylshikimic acids, protocatechuic acid, hydroxytyrosol, hydroxybenzoic acid and their derivatives and method of preparation thereof. World Patent WO 2010/137943: Malaysian Palm Oil Board.

24. Maier VP, Metzler DM \& Huber AF (1964) 3-O-Caffeoylshikimic acid (dactylifric acid) and its isomers, a new class of enzymic browning substrates. Biochem Biophys Res Commun 14, 124-128.

25. Modafar C, Tantaoui A \& Boustani E (2000) Effect of caffeoylshikimic acid of date palm roots on activity and production of Fusarium f. sp. albedinis cell wall-degrading enzymes. J Phytopathol 148, 101-108.

26. Hassni M, Hadrami A, Daayf G, et al. (2004) Chitosan, antifungal product against Fusarium oxysporum f. sp. albedinis and elicitor of defence reactions in date palm roots. Phytopathol Mediterr 43, 195-204.

27. Bastos DH, Saldanha LA, Catharino RR, et al. (2007) Phenolic antioxidants identified by ESI-MS from Yerba mate (Ilex paraguariensis) and green tea (Camelia sinensis) extracts. Molecules 12, 423-432.

28. Hokkanen J, Mattila S, Jaakola L, et al. (2009) Identification of phenolic compounds from lingonberry (Vaccinium vitis-idaea L.), bilberry (Vaccinium myrtillus L.) and hybrid bilberry (Vaccinium $\times$ intermedium Ruthe L.) leaves. J Agric Food Chem 57, 9437-9447.

29. Rice-Evans CA, Miller NJ \& Paganga G (1996) Structure-antioxidant activity relationships of flavonoids and phenolic acids. Free Radic Biol Med 20, 933-956.

30. Vattem D \& Shetty K (2003) Ellagic acid production and phenolic antioxidant activity in cranberry pomace (Vaccinium macrocarpon) mediated by Lentinus edodes using solidstate system. Proc Biochem 39, 369-379.
31. Zheng Z \& Shetty K (2000) Solid-state bioconversion of phenolics from cranberry pomace and role of Lentinus edodes beta-glucosidase. J Agric Food Chem 48, 895-900.

32. Stalmach A, Mullen W, Barron D, et al. (2009) Metabolite profiling of hydroxycinnamate derivatives in plasma and urine after the ingestion of coffee by humans: identification of biomarkers of coffee consumption. Drug Metab Dispos 37, 1749-1758.

33. Richelle M, Tavazzi I \& Offord E (2001) Comparison of the antioxidant activity of commonly consumed polyphenolic beverages (coffee, cocoa, and tea) prepared per cup serving. J Agric Food Chem 49, 3438-3442.

34. Steinberg D, Parthasarathy S, Carew TE, et al. (1989) Beyond cholesterol. Modifications of low-density lipoprotein that increase its atherogenicity. $N$ Engl J Med 320, 915-924.

35. Regnstrom J, Nilsson J, Tornvall P, et al. (1992) Susceptibility to low-density lipoprotein oxidation and coronary atherosclerosis in man. Lancet 339, 1183-1186.

36. Frankel E, Waterhouwe A \& Teissedre P (1995) Principal phenolic phytochemicals in selected Californian wines and their antioxidant activity in inhibiting oxidation of human low-density lipoprotein. J Agric Food Chem 43, 890-894.

37. Osakabe N, Yasuda A, Natsume M, et al. (2002) Catechins and their oligomers linked by $\mathrm{C} 4 \rightarrow \mathrm{C} 8$ bonds are major cacao polyphenols and protect low-density lipoprotein from oxidation in vitro. Exp Biol Med (Maywood) 227, 51-56.

38. Yang TT \& Koo MW (2000) Inhibitory effect of Chinese green tea on endothelial cell-induced LDL oxidation. Atherosclerosis 148, 67-73.

39. Morel I, Lescoat G, Cillard P, et al. (1994) Role of flavonoids and iron chelation in antioxidant action. Methods Enzymol 234, 437-443.

40. Salah N, Miller NJ, Paganga G, et al. (1995) Polyphenolic flavanols as scavengers of aqueous phase radicals and as chainbreaking antioxidants. Arch Biochem Biophys 322, 339-346.

41. Bernatova I, Pechanova O, Babal P, et al. (2002) Wine polyphenols improve cardiovascular remodeling and vascular function in NO-deficient hypertension. Am J Physiol Heart Circ Physiol 282, H942-H948.

42. Chin-Dusting JP, Boak L, Husband A, et al. (2004) The isoflavone metabolite dehydroequol produces vasodilatation in human resistance arteries via a nitric oxide-dependent mechanism. Atherosclerosis 176, 45-48.

43. Grassi D, Aggio A, Onori L, et al. (2008) Tea, flavonoids, and nitric oxide-mediated vascular reactivity. $J$ Nutr $\mathbf{1 3 8}$, 1554S-1560S.

44. Lopez-Sepulveda R, Jimenez R, Romero M, et al. (2008) Wine polyphenols improve endothelial function in large vessels of female spontaneously hypertensive rats. Hypertension $\mathbf{5 1}$, 1088-1095.

45. Suzuki A, Fujii A, Yamamoto N, et al. (2006) Improvement of hypertension and vascular dysfunction by hydroxyhydroquinone-free coffee in a genetic model of hypertension. FEBS Lett 580, 2317-2322.

46. Suzuki A, Yamamoto M, Jokura H, et al. (2007) Ferulic acid restores endothelium-dependent vasodilation in aortas of spontaneously hypertensive rats. Am J Hypertens 20 , 508-513.

47. Whelan AP, Sutherland WH, McCormick MP, et al. (2004) Effects of white and red wine on endothelial function in subjects with coronary artery disease. Intern Med J 34, 224-228.

48. Colarieti M, Toscano G \& Greco G (2006) Toxicity attenuation of olive mill wastewater in soil slurries. Environ Chem Lett 4, 115-118. 